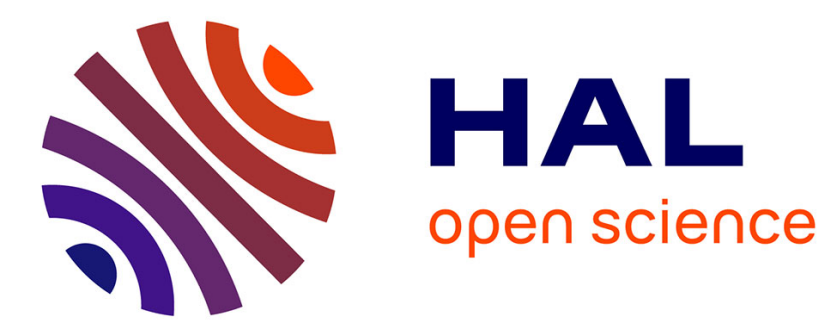

\title{
Characterization of Chipless RFID Tag in a 3- Dimensional Reading Zone
}

Raphael Tavares de Alencar, Nicolas Barbot, Marco Garbati, Etienne Perret

\section{To cite this version:}

Raphael Tavares de Alencar, Nicolas Barbot, Marco Garbati, Etienne Perret. Characterization of Chipless RFID Tag in a 3- Dimensional Reading Zone. 2019 IEEE International Symposium on Antennas and Propagation and USNC-URSI Radio Science Meeting, Jul 2019, Atlanta, United States. hal-02078487

\section{HAL Id: hal-02078487 https://hal.science/hal-02078487}

Submitted on 25 Mar 2019

HAL is a multi-disciplinary open access archive for the deposit and dissemination of scientific research documents, whether they are published or not. The documents may come from teaching and research institutions in France or abroad, or from public or private research centers.
L'archive ouverte pluridisciplinaire HAL, est destinée au dépôt et à la diffusion de documents scientifiques de niveau recherche, publiés ou non, émanant des établissements d'enseignement et de recherche français ou étrangers, des laboratoires publics ou privés. 


\title{
Characterization of Chipless RFID Tag in a 3- Dimensional Reading Zone
}

\author{
Raphael Tavares de Alencar, Nicolas Barbot, Marco Garbati, Etienne Perret, Senior Member, IEEE \\ Univ. Grenoble Alpes, Grenoble INP, LCIS 26000 \\ Valence, France. \\ \{raphael.tavares-de-alencar, nicolas.barbot, marco.garbati, etienne.perret\}@1cis.grenoble-inp.fr
}

\begin{abstract}
In this paper, we present the characterization of the reading volume for a chipless RFID system. S21-parameter measurements were done in real environment with a fixed antenna and moving tag inside a $30 \times 30 \times 30 \mathrm{~cm}^{3}$ volume, the result obtained is the reading zone for the given setup. A qualitative analysis is done, pointing out its resemblance to the radiation pattern of the antenna and the implications on the tag's readability in a 3-dimensional range. In this study, we have shown that the maximum reading distance could be as high as $30 \mathrm{~cm}$, and that the largest reading area is approximately $300 \mathrm{~cm}^{2}$ with a read success rate of $40 \%$ inside that area, for a distance of $15 \mathrm{~cm}$.
\end{abstract}

Keywords- Chipless RFID; RCS Measurement; Tag Characterization; Reading Volume; UWB

\section{INTRODUCTION}

Chipless RFID has become an ever-advancing topic of research, considering it proposes an automatic identification solution which can compete with the traditional barcode systems, allowing non-line-of-sight reading while maintaining a low cost when compared to traditional RFID systems. Similarly to the aforementioned identification systems, a chipless RFID system is composed by: a tag - containing a particular resonating structure; a reader - which sends an interrogation signal and receives the signal reflected by the tag; and a database - which decodes the information received and associates it to a unique identifier [1]. Much research is dedicated to increasing the coding capacity of tags and reducing their dimensions, as can be seen in [2], generally pointing out their time- or frequency-responses. Some work, mainly focused on the reader, mentions the system's read range, for a tag centered in front of the antenna, as seen in [3].

In this work we focus on the characterization of the volume in space in which a chipless RFID tag is correctly decoded, analyzing results obtained in an extensive measurement campaign with the tag positioned inside a $30 \times 30 \times 30 \mathrm{~cm}^{3}$ volume.

\section{SETUP DESCRIPTION}

The setup configuration used can be seen in Fig. 1. The setup was placed in a real environment, surrounded by objects, without use of any absorbent material.

The antenna is positioned facing upwards on a fixed arm, in a monostatic configuration. The antenna used is a dualpolarization wideband open-boundary quad-ridge horn (SATIMO QH2000), which can operate in the 2-32 GHz band and has gain varying from 6 to $11 \mathrm{dBi}$ along the interest bandwidth, from 2 to $10 \mathrm{GHz}$. This antenna is connected to a FieldFox Handheld Microwave Analyzer (Keysight N9918A), with an output power of $0 \mathrm{dBm}$. Port 1 is connected to the vertical polarization antenna port for transmission, while port 2 is connected to the horizontal polarization for reception. Therefore the S21-parameter provides the tag response in cross-polarization (VH). The tag is placed facing downwards, on the end of a mechanical moving arm, which is softwarecontrolled. The tag's initial position is centered in front of the antenna, at a $0.2 \mathrm{~cm}$ range, corresponding to an initial position given by coordinates $\left(x_{i}, y_{i}, z_{i}\right)=(0,0,0) \mathrm{cm}$. The arm was then displaced inside the volume determined by $x \in[-15 ; 15] \mathrm{cm}, y \in[-15 ; 15] \mathrm{cm}$ and $z \in[0 ; 30] \mathrm{cm}$, corresponding to the red box drawn in Fig. 1. The displacement step applied was of $1 \mathrm{~cm}$, one axial direction at a time. A total of 29791 measurements were performed, each for a separate set of coordinates inside the described volume.

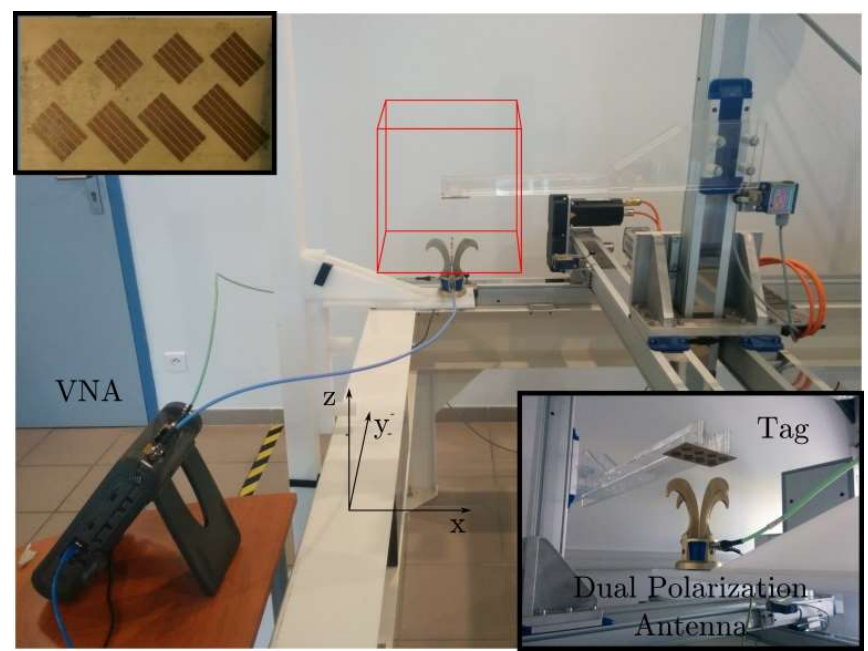

Fig. 1. Setup Configuration in real environment.

For each position, we measure the response of the tag and we subtract an "empty" measurement, which was performed previously, only once, without presence of the tag. This is done to mitigate the direct coupling between the antennas, and the effects of the environment $[3,4]$. All acquisitions were done without use of time-gating techniques.

For this study, all the measurements were done using the depolarizing tag presented in [4], shown in the top left corner of Fig. 1. This tag was realized with a $0.8 \mathrm{~mm}$ RO4003 substrate $\left(\epsilon_{R}=3.55, \tan \delta=0.0025\right)$ and ground plane, and has a total surface of $8.5 \times 5.3 \mathrm{~mm}^{2}$. It contains eight independent resonators, each resonator being composed of a set 
of five identical shorted stripline dipoles, oriented at $45^{\circ}$. Each of these resonators is associated to a single peak in frequency, between 3 and 7GHz. The tag's code is determined by the position of these eight resonances, which are given by the lengths of each set of dipoles.

\section{RESULTS AND ANALYSIS}

In this section, the decoding method for the tag used is first presented, followed by the description and evaluation of the reading volume. Fig. 2(a) and (b) show two examples of a S21 measurement for the previously described tag. To decode this tag, the overall bandwidth is divided among 8 bands of 400 $\mathrm{MHz}$, which in turn are divided in 4 sub-bands of $100 \mathrm{MHz}$ each. The position of the peak in each band determines 2 bits of the resulting code, except the eighth resonator which has only two possible bands and can encode a single bit (thus determined due to its low Q factor). Hence, the total capacity of this tag is 15 bits. Fig. 2(a) presents a correct reading of the tag, for position $(0,0,13) \mathrm{cm}$ where each peak is located in the correct sub-band to encode all zeros (indicated by a green rectangle).Fig. 2(b) shows an incorrect reading of the tag, for position $(1,-6,13) \mathrm{cm}$ where the fourth peak is incorrectly decoded as " 11 ".
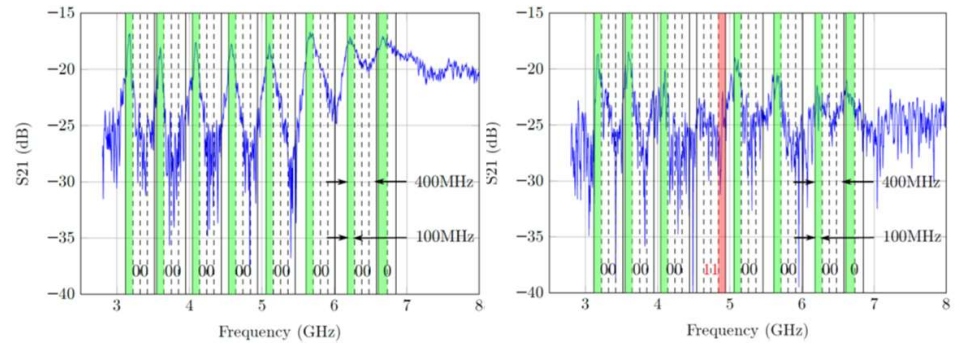

Fig. 2: S21 measurement: (a) Example of correct reading of the chipless RFID tag at $(0,0,13) \mathrm{cm} ;(\mathrm{b})$ incorrect reading at $(1,-6,13) \mathrm{cm}$.

In Fig. 3(a) we can see the volume in which the tag can be correctly read. Blue markers correspond to correct reading of the tag while the absence of a marker indicates positions where the tag was not read. We can see that when the tag is in close proximity of the antenna (e.g., $z=1 \mathrm{~cm})$, the area in which it is read is small and centered directly in front of the antenna, as $z$ increases and the tag is farther from the antenna, the corresponding reading area also increases. Note that the tag can be correctly read in near-field region. However, for a qualitative comparison, we also present the measured radiation pattern of the SATIMO QH2000, Fig. 3(b). We can see that the reading volume is linked to the radiation pattern of the antenna. Even though the reading area increases with distance, when the $z>20 \mathrm{~cm}$ we notice that even in the area centered in front of the antenna the tag could be incorrectly decoded, this is due to the lower received power at these distances. Therefore, there is a compromise between the reading area and the capacity to correctly read the tag. To illustrate this compromise, we define the reading area as a rectangle which includes all correct readings performed in that plane, and the read success rate is given by the the number of correct readings over the number of positions inside this area. Results are presented in Fig. 4, for different planes, and summed up in Table 1 . We can see that the reading area reaches over 300 $\mathrm{cm}^{2}$ for $z \geq 15 \mathrm{~cm}$. The read success rate starts to decrease for $z \geq 25 \mathrm{~cm}$.
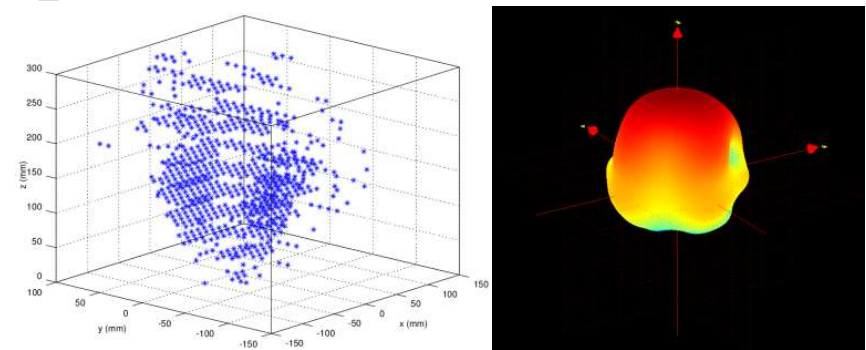

Fig. 3. 3D characterization: (a) Representation of the volume in which the tag is correctly read; (b) Radiation pattern measured for vertical horn of the antenna, at $5.5 \mathrm{GHz}$

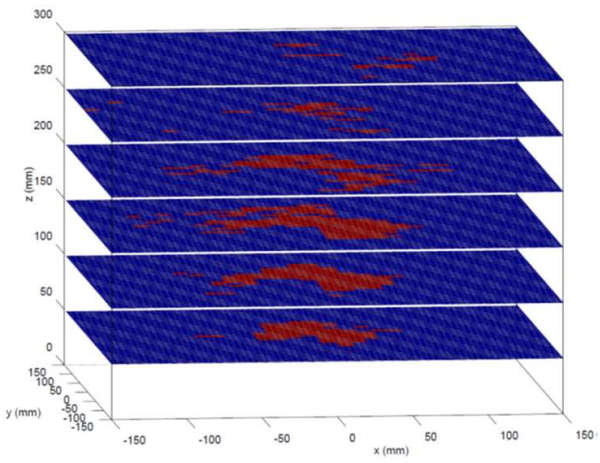

Fig. 4. Positions where the tag was successfully read (in red) for different $x y$-planes.

TABLE I. READING AREA AND SUCCESS RATE FOR DIFFERENT DistANCES

\begin{tabular}{|c|c|c|c|c|c|c|}
\hline $\boldsymbol{z}(\mathbf{c m})$ & $\mathbf{5}$ & $\mathbf{1 0}$ & $\mathbf{1 5}$ & $\mathbf{2 0}$ & $\mathbf{2 5}$ & $\mathbf{3 0}$ \\
\hline Area $\left(\mathbf{c m}^{2}\right)$ & $13 \times 13$ & $17 \times 14$ & $18 \times 18$ & $18 \times 19$ & $18 \times 18$ & $9 \times 18$ \\
\hline Success Rate & $40.8 \%$ & $39.0 \%$ & $40.0 \%$ & $29.5 \%$ & $11.0 \%$ & $14.2 \%$ \\
\hline
\end{tabular}

\section{CONCLUSIONS AND FUTURE WORK}

In this paper, we have characterized a 3-dimensional reading zone for a chipless RFID system, determined the maximum reading distance, reading areas and corresponding success rates for different distances, we have seen that these results are linked to the antenna's radiation pattern and have shown that there is a compromise between these factors. We also have seen that reading can be done in near-field, more exactly in regions where EM power density is high.

Future work can take into account differences observed in the reading volume for tags with and without ground plane; compare the performance of different decoding techniques; include a vaster study, involving the tag's orientation relative to the reader antenna; perform a similar study for a system comprised of the tag and a low-cost chipless RFID reader [3].

\section{REFERENCES}

[1] E. Perret, "Radio Frequency Identification and Sensors: From RFID to Chipless RFID,”. John Wiley \& Sons, 2014.

[2] I. Aminul, N. C. Karmakar. "A novel compact printable dual-polarized chipless RFID system." IEEE Trans. Microw. Theory Techn., vol. 60, no. 7, pp. 2142-2151, 2012

[3] M. Garbati, E. Perret, R. Siragusa. "Chipless RFID Reader Design for Ultra-Wideband Technology: Design, Realization and Characterization". ISTE - Elsevier, 2018.

[4] A. Vena, E. Perret and S. Tedjni, "A Depolarizing Chipless RFID Tag for Robust Detection and Its FCC Compliant UWB Reading System," in IEEE Transactions on Microwave Theory and Techniques, vol. 61, no. 8, pp. 2982-2994, Aug. 2013. 